\title{
Effective drinking water collaborations are not accidental: interagency relationships in the international water utility sector
}

\author{
D I Jalba ${ }^{\mathrm{a}}$, N J Cromar ${ }^{\mathrm{b}}$, S J T Pollard ${ }^{\mathrm{c}}$, J W Charrois ${ }^{\mathrm{d}}, \mathrm{R} \mathrm{Bradshaw}^{\mathrm{c}}$ and S E Hrudey ${ }^{\mathrm{e}}$ \\ ${ }^{a}$ School of Medicine and ${ }^{b}$ School of the Environment, Flinders University, GPO 2100, \\ Adelaide, SA 5001, Australia \\ ${ }^{c}$ Cranfield Water Science Institute, Cranfield University, Bedfordshire, MK43 OAL, UK \\ ${ }^{d}$ Curtin Water Quality Research Centre, Curtin University, GPO Box U1987, Perth, \\ WA 6845, Australia \\ ${ }^{e}$ Analytical \& Environmental Toxicology Division, Faculty of Medicine \& Dentistry, \\ 10-102 Clinical Sciences Building, University of Alberta, Edmonton, AB, T6G 2G3, Canada
}

\begin{abstract}
The role that deficient institutional relationships have played in aggravating drinking water incidents over the last 30 years has been identified in several inquiries of high profile drinking water safety events, peer-reviewed articles and media reports. These indicate that collaboration between water utilities and public health agencies (PHAs) during normal operations, and in emergencies, needs improvement. Here, critical elements of these interagency collaborations, that can be integrated within the corporate risk management structures of water utilities and PHAs alike, were identified using a grounded theory approach and 51 semi-structured interviews with utility and PHA staff. Core determinants of effective interagency relationships are discussed. Intentionally maintained functional relationships represent a key ingredient in assuring the delivery of safe, high quality drinking water.
\end{abstract}

Keywords: drinking water, incidents, risk, public health, emergency management 


\section{Introduction}

Public health protection must be the principal goal of a drinking water utility (IWA, 2004; WHO, 2011). The goal to provide safe drinking water in sufficient quantity and at good aesthetic quality (IWA, 2004) may be challenged by a plethora of natural and manmade adverse events and hazards, either in the catchment, or along the water treatment and distribution chain. These include drought, floods, fires, storms and hurricanes, spring melting and runoff, animal or human faecal contamination, algal blooms, chemical or radiological leaks, water treatment equipment failure, pipe breaks, operator error, vandalism, terrorism, and so on (Bartram et al., 2009; Emde et al., 2006; Herrick et al., 2006; Hrudey and Hrudey, 2004; IWA, 2004; Jalba et al., 2009; Pollard et al., 2007; USEPA, 2004b; WHO, 2011). For many utilities, the goal of public health protection is challenged by a wide range of other business risks. Water utilities must remain ecologically, environmentally and economically sustainable, as well as financially profitable and competitive for private water companies (CEC, 2000; Middleton and Saunders, 1997; Pollard et al., 2009; Pollard et al., 2007). Finally, as providers of an essential public health service, water companies must preserve regulatory as well as consumer trust, having to manage multiple perception risks, irrespective of their tangible health impacts (IWA, 2004; Mobley et al., 2006; Parkin et al., 2006; Parkin et al., 2004; Pollard et al., 2009). All these risks need to be assessed and integrated at corporate level, and the water utility must prevent and/or manage them to protect public health (Bartram et al., 2009; IWA, 2004; Jalba et al., 2009; Maxwell, 2004; Pollard et al., 2009; USEPA, 2004a; WHO, 2011; Pollard et al., 2013).

Trade-offs are a necessary requirement of drinking water management (Hrudey, 2004), but the clarity of strategic corporate objectives may suffer under the complexities of regulatory incentives, organizational structures, the debt financing of the asset base and split accountabilities (e.g. outsourcing) (Pollard et al., 2009; Pollard et al., 2007). Furthermore, risk factors that might compromise the overarching mission can lie undetected within organizations, acting as latent precursors for water quality incidents and other adverse events (Pollard et al., 2009; Reason, 1997). Managing risk, therefore, is more complex than just optimizing asset management, completing risk registers, ensuring compliance or managing chemicals in catchments; it requires vigilance at all levels within a utility, focused around unambiguous business goals (Pollard, 2008).

Some of these challenges can be addressed technically, for example, by installing better water treatment and upgrading infrastructure, developing new technological solutions for new and emerging pathogens or through better water quality monitoring systems (Rizak and 
Hrudey, 2007; USEPA, 2005; WHO, 2011). Others are business-related and require sustainable and environmentally responsible strategies, new ways to maintain profitability, and to ensure occupational health and safety (Pollard et al., 2004; 2007). Others involve responding to external challenges such as ensuring consumer satisfaction, collaborating with stakeholders (including regulatory agencies) and through well-managed media relations (Hrudey and Hrudey, 2004; Hrudey et al., 2006; Jalba et al., 2009). There are also challenges for emergency management and catchment protection that involve a combination of technical, business and external solutions (Bartram et al., 2009; Jalba et al., 2009).

We have previously identified six components that may be deficient in the relationship between affected water utilities and their respective public health authorities (PHAs): (1) proactivity; (2) knowledge exchange; (3) trust; (4) regular communication; (5) joint training; and (6) a supportive regulatory environment (Jalba et al., 2010). We indicated that international and national guidelines, supportive regulations, and local communication arrangements do not, by themselves, guarantee effective interagency collaboration, though they do present opportunities to develop meaningful (as opposed to cursory or superficial) collaboration (Jalba et al., 2010). We distinguished a collaborative strategy (intent) from a collaborative structure (for delivery). To be effective, any structure must adopt an agreed strategy (Krames, 2008); that is, the relationship must have a defined purpose and a means of achieving it.

Here, we report findings from in-depth interviews with senior drinking water and PHA managers from a selection of reputable organisations from Australia, Canada, the United States, and the United Kingdom, on the topic of achieving effective interagency collaborations. Many of the participating organisations had been involved in managing drinking water incidents that challenged their existing collaborative agreements and provided lessons and opportunities to optimize their approach. To our knowledge, this is the first indepth study of this kind, and the research has broad international relevance for researchers, practitioners and policy-makers seeking to strengthen water safety, business resilience and risk governance in the international water sector.

Prior research has identified a number of drivers, tools and determinants governing successful inter-organisational collaboration relevant to the area of drinking water. Rather than explore failings, that have been addressed elsewhere by the authors, our aim here was to identify effective practices.. Building on the work of Hrudey and Hrudey (2004), Parkin et al.(2006), Cash et al. (2003), and Thomson et al. (2009), we seek to identify the critical elements of interagency collaboration that can be integrated in the overall corporate risk 
management approach of water utilities (Pollard, 2013) and PHAs alike, principally for the purposes of promoting a standard for meaningful interactions between utilities and agencies as a means of helping them discharge their mandates successfully. We offer insights to an international audience on (i) the critical institutional relationship deficiencies that may aggravate a drinking water and health emergency situation; (ii) the determinants of a successful effective relationship between a water utility and its respective PHA(s); and (iii) how an effective collaborative relationship can be integrated with the risk management culture of a water utility as an effective means of delivery.

\section{Methods}

\subsection{Study rationale and participants}

We employed a qualitative research methodology (Miller et al., 2004; Morse and Field, 1995; Silverman, 2001). An ethnographic approach would have unnecessarily broadened data collection, and participant observation. Observing single water professionals in public health risk management would have been unrealistic, since most utilities may not even experience one drinking water and health incident per year serious enough to warrant a significant interaction with their PHA. Drinking water and health incidents in affluent countries are rare and unpredictable; therefore, field research would have produced limited data. Our choice was to adopt a grounded theory method (GTM) adapted to the risk management focus of this research (Trochim, 2006). Participating organisations from English-speaking countries were selected based on being organisations: (i) covering various geographical areas, in terms of climate, water resources, cultural profile, urbanisation and socio-economic development; (ii) operating in various jurisdictions, with different laws and regulations relevant to the aims of the study (e.g. regulatory environment, regulatory agencies, emergency preparedness, specific safe drinking water legislation); and (iii) able to provide a water utility - PHA pairing. Interviewees (see Supplementary Information, SI-T1) were selected based on them: (iv) occupying key risk management positions in their organisation; and (v) working at the interface with other agencies in relation to public health risks. Atypical participants were accepted for comparison and contrast (e.g. former occupants of key positions).

\subsection{Data collection and analysis}

Using purposive sampling, we conducted 40 in-person, semi-structured interviews employing open-ended questions between November 2006 and March 2008. Overall, we 
interviewed 51 professionals from Australia, Canada, the United Kingdom and the United States (SI_T1). Questions were organized in six sections (general institutional data, risk management policy and implementation, interagency relationships, past incidents and nearmisses of public health relevance, emergency management, and training and assistance). Prior ethics approval for the study design, interviews and the handling of research data was secured through Flinders University Social and Behavioural Research Ethics Committee.

The research instrument was tested through a pilot interview with a typical participant, and reviewed before data collection began. Minor adjustments were employed to add clarity. Our analysis sought to identify current critical gaps and constructive processes that would cover the shortcomings recognized in the survey of past drinking water and health incidents described above. When opportunity occurred during interviews, additional incidents and unpublished aspects of some incidents identified through previous literature survey were clarified with reference to interagency relationships. Concepts were identified according to the lead author's (DJ) judgement. They were reviewed and verified with public health and drinking water experts. Purposive sampling may have limited the generalisation of our results to the water industry as a whole, but the consistency of our findings provides evidence of recurrent themes that segments of the water industry and PHAs ought to consider when seeking to improve interagency relationships. Our GTM approach was iterative (Goulding, 2002). Systematic analysis of qualitative data (e.g. interview conversations) sought to develop a supportable means of answering our research questions, and was achieved through coding, memo-ing, and concept mapping. Interview data was initially open-coded, with selective coding employed later as concepts developed. In addition to triangulation within the research team, study findings were reviewed by independent water experts from each participating country, including an US-based water industry expert panel who confirmed the relevance of critical data categories used during the analysis and validated study findings.

\section{Results}

Our findings present the high level principles that transcend national regulatory environments, operating structures, legal entities and local cultures. Where appropriate, divergent findings between similar organisations in different countries are reported. Our main results are presented and discussed below, with additional survey results presented in the Supporting Information (SI) online. The references section contains a full bibliography for the main text and SI and is intended a bibliographic reference to readers on this specific topic of interest. 


\subsection{Risk management culture}

Most commonly, water utilities defined their mission as providing safe and aesthetically pleasant, high quality drinking water. Other aspects included cost-efficiency, excellent and reliable service, and environmental responsibility. PHA representatives most often defined their organisation's mission on drinking water as being to protect public health by ensuring safe drinking water and minimising human public exposure to drinking water hazards. Other aspects mentioned were being informed early of drinking water events that may affect public health, working with water utilities, and coordinating emergency response.

Interviewees were asked to self-assess the development of a 'risk management approach' to drinking water in their organisation. Half of water utility interviewees stated they followed a formal risk management approach to drinking water at all levels. Minority views included beliefs they were employing a risk management approach for individual water systems, but not at corporate level (one-sixth) or alternatively, that they were employing a risk management approach at corporate level, but not related directly to drinking water (onesixth). Most notably, one quarter of interviewees reported not employing a formal risk management approach at all in their organisation; this view mostly expressed by the United States and some Canadian utilities. However, all interviewees reported having developed emergency response plans (ERPs) for their drinking water operations.

By contrast, over half of PHA interviewees reported not employing a formal risk management approach within their organisations; such responses came from PHAs from all participating countries. One quarter of interviewees, although not having a formal risk management approach for drinking water, were promoting water safety plans (WSPs) among water utilities in their jurisdiction, whilst the remainder reported employing a formal risk management approach at corporate level, but not specifically for drinking water. One quarter of total PHA interviewees, however, reported having developed 'vulnerability assessments' related to water security in their jurisdiction, most commonly in the US.

While most water utility interviewees affirmed they regularly apply risk management in taking public health decisions, in many cases this would refer more to having standard operating procedures (SOPs) or manuals rather than an explicit, risk-based approach to issues. The same applied to some of the PHAs interviewed, while the majority would typically refer to the public health precautionary principles and paradigm. Only a few PHA representatives expressed the importance of risk trade-offs when dealing with environmental health issues. 
Most UK utilities and one Canadian utility reported having their risk managers focused on business risks. These utilities have in place formal comprehensive risk management programs for the whole business, whose focus is often on financial and commercial risk. Public health risk is rarely elaborated explicitly, although most organizations would have public health included in their mission statement and principles. In contrast, most US and Canadian utilities did not have a centralised risk management program or a risk management policy document at the time of interview (i.e. June 2007 and November 2006, respectively). Their organisational culture seemed to be driven primarily by regulatory requirements that promote compliance monitoring rather than overall risk management. Half of these utilities practiced implicit risk management by adopting proactive programs to address certain highrisk segments (e.g. cross-connections). Identified risk managers would usually focus on emergency preparedness for potential terrorism and natural disasters, and on health and safety.

The use of risk terminology does not necessarily imply a risk management 'culture' (Pollard et al., 2007) and the meaning that interviewees attributed to risk concepts seemed to vary greatly. A consistent and mutually agreed application of risk management principles to public health risks by both sides remains elusiveand this may well lead to uneven participation in decision-making, with one party having to more-or-less accept what the 'experts' on the other side have already agreed on.

\subsection{Interagency relationships}

\subsubsection{Partner risk management approach}

Most utility interviewees considered their respective PHAs did not employ a risk management approach in the activity of their own organisation related to drinking water safety. In one US case, the interviewee believed their PHA would use risk management for water security. Many utility interviewees regarded PHAs as being risk-averse, whereas risk 'management' for a PHA might be interpreted as a need to weaken public health protection standards. This seemed to relate to the precautionary paradigm that a typical PHA would use (Emde et al., 2006; Jalba and Hrudey, 2006) reflected in these cases by a reluctance to recognise explicit risk trade-offs. By contrast, two interviewees recognised that implicit trade-offs remain a necessary part of providing a water service that need not compromise overall public health protection.

Water utility answers were generally confirmed by PHA interviewees in paired organisations. No PHA staff reported explicit risk management in their own organisation as 
it relates to their own activity of supervising drinking water safety, although a few expressed a belief that they practice risk management implicitly. The most common answer, of about half of PHA interviewees, was that they do not know whether they use a risk management approach. While the question of implicit risk management remains open, the PHA answers clearly indicated their organisations had no systematic approach to risk management.

In paired organisations, half of the PHA interviewees believed their utility counterparts follow a risk management approach, while most of the remainder affirmed ignorance on this point. In two cases, the PHA interviewees expressed a belief that the utility follows a risk management approach, whereas the respective utility representatives disagreed. Conversely, a formal risk management approach was employed in a quarter of paired utilities, but their PHA counterparts did not recognise this. In only three cases did both parties agree that the respective utilities follow a structured, formalised risk management approach that was confirmed upon further probing.

Many interviewees, particularly on the PHA side, were not very familiar with risk management concepts and their application to drinking water safety. The language of risk has often been employed liberally, to mean anything from emergency protocols to public communication, but not necessarily to the adoption of a formalised risk management approach to assure prevention, mitigation and control of drinking water incidents. The limited recognition of the role of risk management in the area of drinking water quality may help explain contradictory statements in paired organisations about what their counterpart does on risk management. This finding raises doubts about whether the interactions resulted in meaningful knowledge transfer and truly promoted prevention in all aspects related to drinking water incidents.

\subsubsection{Quality of interagency collaborations}

All interviewees self-characterised their inter-organisational relationship as positive, in varying degrees. To some extent, this may represent a sampling bias related to their agreement to be interviewed for this research. Because participation in the study was voluntary, professionals were more comfortable with their interagency relationships and may have been more likely to accept participation. In some cases, interviewees from both sides appreciated their relationship was somewhat restricted by the limited interest of the PHA in drinking water issues, compared to other demanding public health matters (e.g, sexuallytransmitted diseases, illicit drug use, food safety, chronic illnesses, immunisations). Finally, 
changes in the quality of the relationship, resulting from key staff changes, indicated that the institutional relationship was frequently immature and relied on personal connections.

The two sets of interviewees generally matched each other in terms of the reported intensity of interaction. In particular, approximately half from each side estimated they were in weekly contact with their counterparts. At the other extreme, a significant finding was that in a minority of participating organisations, the relationship is driven only by drinking water safety incidents, i.e. it is entirely reactive.

Identifiable results of institutional cooperation (such as joint emergency response protocols, other written agreements or joint projects) were reported by each side, with utility interviewees reporting activities in a higher proportion than their PHA counterparts. This is not necessarily surprising since not all organisations were paired in this study, and even in paired organisations cooperative activities were not always equally reported by both parties. However, the comparatively less frequent reporting by PHAs of concrete activities that demonstrate cooperation (beyond discussing compliance monitoring results), may suggest that issues beyond strict compliance are viewed as less important to their interaction. Actors engaged in a meaningful, as opposed to cursory or superficial, interaction would be more likely to recognise such activities as central to the purpose of developing a mature, stable institutional relationship.

As a further step in formalising the institutional relationship, several Australian utilities had developed memoranda of understanding (MoUs) with their state health departments. The content of these MoUs varied, but generally defined roles and responsibilities for each party during both normal times and in emergencies, formalised information exchange, and mandated regular contact and cooperation. Creating an MoU was a condition set in the operating licence for these utilities. Among interviewees from the other countries, there was only one identified case in the US, a tri-lateral agreement between the water utility, state and county PHA that defined roles and expectations during normal and emergency times. Another tri-lateral MoU was identified in one UK case between the water utility, water quality regulator and environmental regulator in relation to catchment management arrangements.

\subsubsection{Relationship development}

Several interviewees commented that before the 1990s, it was generally assumed that water utilities had all the expertise necessary to produce safe water, and they were expected to operate without much need for external input. This approach was not optimal for 
protecting public health. For example, several Canadian participants (from both utilities and PHAs) insisted that the deficient relationship between oversight agencies and the Walkerton water system operators (O'Connor, 2002a) was typical for the kind of relationships that PHAs had with water utilities during the 1980s and 1990s. Another participant stated, in this context: "In 1995 I went to a health inspectors conference in Ontario on the topic of water and I asked the audience how many have visited a water treatment plant-nobody put their hand up. In the 90s all that the health departments would do is look at the water results, but never went to a water treatment plant to understand the system. To me that did not make any sense, because you cannot judge the water only based on a $200 \mathrm{~mL}$ sample".

Most interviewees indicated that relationships between water utilities and PHAs have developed gradually in the past two decades. Various events helped shape that process, providing more visionary managers with opportunities for strengthening the institutional relationship (Table 1).

\section{[TABLE 1 HERE PLEASE]}

Most water utility interviewees reported the institutional relationship developing because both parties had responded to a significant drinking water and health incident (Table 2). Relationships between the two parties prior to the respective event were never reported as antagonistic. In most cases, both organisations had been operating for many years, with limited input from the other party. For some utilities the importance of having a meaningful, ongoing contact with the PHA became clear after they 'came under fire' from media and concerned citizen groups for failing to provide a satisfactory response to issues such as protecting AIDS patients from exposure to Cryptosporidium, or children from lead contamination in the water supply. In one case, political interference disrupted the incident command process by adding pressure to an already stressful situation, by setting unrealistic expectations (e.g. shorter timelines for lab results than can scientifically be expected, since bacteria do not grow as fast as politicians may want them to), and by trying to influence public health decisions.

The respective incidents nevertheless triggered, on both sides, a realisation of the importance of establishing a regular relationship prior to incidents in order to improve future responses. Generally, the critical incident was resolved without serious public health consequences. However, difficulties occurred during the process relating to misunderstandings, unnecessary mutual criticism, distrust and unnecessary delays resulting, among others, from uncertainty about what the other party does or was intending to do. 
Lastly, a role for relationship advocates (committed managers) emerged as a prominent factor. Over half of the paired organisations recognised the role that committed managers on both sides had over the years in seeking ways to connect, define, maintain and strengthen the bilateral relationship. While the relationship was eventually formalised through bilateral agreements in only half of the cases described in interviews, in all these cases the relationship was regular and meaningful.

\subsection{Emergency management}

No systematic approach to addressing specific relationship components through targeted scenarios was identified by participating utilities. Exercise scenarios seemed to be designed and driven primarily by operational needs and the emergency concerns of the moment. The purpose of developing relationship elements (e.g. trust) was not addressed, but either assumed to pre-exist or expected to develop naturally in the course of operational exercises. Furthermore, many utilities seemed to have formulated emergency preparedness plans, but not actually tested them. Interagency relations were not always addressed in the planning. Practising these plans by superficially going through the steps in the protocol provides little assurance that the adequate organisational culture, institutional communication and support systems are in place to support effective emergency response.

Organising more complex exercises or drills does require more effort, but meaningful practise provides organisations with the opportunity to identify weaknesses and update their plans. On the other hand, a passive attitude and relying on external bodies to organise such exercises may leave many significant relationship gaps unmitigated. For example, scenarios such as malicious contamination of the water source may be popular with emergency services agencies but are unlikely to be representative for the typical challenges that utilities (and PHAs) are confronted with more commonly in their efforts to maintain a safe drinking water supply.

As an example of an ineffective way to organise an exercise, in one case the municipality organized an emergency preparedness drill using a scenario of intentional contamination of the source water with cyanide. The drill involved various city agencies and the local PHA, but the city water utility was not involved in either the planning or execution stages. Thirty minutes into the exercise it was realized that it was extremely difficult to introduce enough chemical contaminant into the water supply to pose a credible health threat to the population; thus the scenario made little sense. The exercise was abandoned. The scenario should have been developed with expertise from the utility, and should have employed priority risks from 
within their vulnerability assessment process. For optimal effect, the scenario should have been designed in a manner that would challenge interagency relationships, such as when available data on contamination is limited and subject to divergent interpretations from various professional perspectives (e.g. water system engineering vs. public health). PHAs were, in general, less involved in testing their emergency preparedness arrangements in relation to drinking water than were utilities. This is consistent with earlier reported findings about PHAs being less committed to the institutional relationship development in this area compared to utilities, because of their competing public health priorities. All participating water utilities would inform their respective PHA immediately if public health consequences from consuming drinking water were suspected, such as from adverse monitoring results, a water treatment barrier failure, or a source water contamination event. The same would apply for security incidents, even if no contamination was detected. The utility would then seek PHA input on assessing health risks. Most utilities indicated that they would prefer to take proactive steps regardless of possible reputation damage, even to calling a boil water advisory (BWA), thus demonstrating due diligence. One utility participant commented: "Due diligence approach means that we prefer to take action, e.g. call a BWA, even if uncertain. In a court, I'd rather defend myself on the basis that as soon as we heard of this, we took action, rather than explain that we waited for two weeks to tell the public - much higher liability!"

Participants were also questioned on whom they would expect to lead risk communication to the public in drinking water and health incidents. There was limited consensus on this issue even in the same country, and not even in paired organisations. Generally, water utilities would hope that the PHA takes the lead for public health notifications and related public communication, but only a few utilities had formal arrangements with PHA in this regard.

Research interviews included a section where the interviewer (DJ) introduced between one and three scenarios based on past drinking water incidents and adapted to local conditions and asked the interviewee to comment on aspects of their emergency response related to institutional collaboration. On analysis of interview responses to these adapted incidents, those interviewees from organizations with a formalised and structured approach to their relationship with PHAs generally seemed to have better appreciation of the mutual needs and the challenges that an incident would present to their relationship. By contrast, interviewees from utilities characterised by a more improvisational approach to risk management and interagency relations failed to observe potential relationship challenges (e.g. miscommunication, conflicting interpretations of limited data available, political interference) 
and sometimes projected an unwarranted over-confidence in their ability to manage relationships during an incident. Similar attitudes were present in the utilities involved in past incidents that experienced relationship difficulties. Unwarranted confidence, in particular, was noted previously in several incidents (Jalba et al., 2010).

\subsection{Mutual expectations}

To better understand relationship determinants, we explored the expectations of water utilities and PHAs in a drinking water incident from each others' perspectives. PHA expectations of the water utility are summarised comparatively to utility beliefs about the same in Table 2. Utility expectations and beliefs of the PHA are listed in Table 3.

\section{[TABLE 2 HERE PLEASE]}

\section{[TABLE 3 HERE PLEASE]}

The expectations in Tables 2 and 3 helped identify many grey areas where the responsibility is either shared, expected to be shared, or may be an overlapping area of interest that only becomes apparent in a more challenging incident. Prominent examples include dealing with unusual contaminants, public notification or linking epidemiological analysis with water system operational findings.

Many of the expectations listed in the tables are not easy to fulfil for every incident. The analysis of incidents presented previously (Jalba et al., 2010) indicate that utilities sometimes experience difficulties in relation to identifying and isolating the source of the contamination, unconditionally supporting a prolonged or 'blanket' boil order (i.e. precautionary covering many areas where the risk is highly unlikely, but cannot be entirely excluded), deciding what is the appropriate amount of information that needs to be shared with other agencies, or corroborating epidemiologically-derived indications of water supply contamination with evidence of possible water system barrier failures.

On the PHA side, there were equal indications of potential difficulties on expectations such as providing the location of cases (for privacy concerns); assessing population health impact; providing health education on water safety risks; justifying the epidemiological link of an outbreak to the water supply beyond reasonable doubt; presenting a unified front in public when there is disagreement or uncertainty related to the source of population exposure to a contaminant; judging the risk of transmission via water in comparison with other 
exposure pathways; appreciating the potential of certain pathogens to be transmitted through the water supply; and even providing laboratory support for detecting pathogens that may be routinely detected in clinical samples but for which a detection method from water samples may not be available (e.g. emerging pathogens, or pathogens that are usually not transmitted through water). In particular, several PHA interviewees appreciated that typical medical and public health training often does not sufficiently cover drinking water treatment, environmental health risk assessment and risk management to enable public health personnel to respond appropriately to some of the above expectations, such as advising on water treatment improvements; treatment removal effectiveness for new or emerging pathogens, for pathogens that are usually not transmitted via water, or for new or unusual chemicals that may contaminate the supply; or providing a health risk assessment for some of the previously mentioned categories of chemicals or pathogens. Of note, most participating organisations failed to recognise many of the expectations that the other party may have for them. A reasonable matching of expectations was only identified in six cases of paired organisations (out of fourteen pairs).

\section{Discussion}

In a world of increasing interdependence, good inter-organisational collaboration plays an important role in fulfilling the mission for most organisations (Bardach, 1998; Gray, 1989). This applies to all players in drinking water, particularly water utilities and their oversight agencies (IWA, 2004; Parkin et al., 2006). While the technical task of producing drinking water belongs to the water utility only, the mission of producing "good safe drinking water that has the trust of consumers" (IWA 2004) requires the cooperative effort between a utility and its stakeholders, particularly public health agencies. In developing countries, institutional disagreements about this responsibility (WHO, 2000) represent a significant barrier to water supply management.

A critical aspect of institutional sustainability is the capability to manage risks. A comprehensive risk management approach can be achieved by including several risk categories (namely financial, commercial, public health, environmental, reputation and legal risks) along with operational risks (Pollard et al., 2004; 2013). An optimal relationship with PHAs aims to prevent not only public health, but also reputational and legal risks. Good relationships with water regulators are vital to building consumer confidence (IWA, 2004; Pollard et al., 2004). Developing an effective collaborative relationship with PHAs may be regarded as one of the critical tests of the maturity of the overall risk management culture in a 
water utility (IWA, 2004; Williams and Hrudey, 2007). Good interagency relations become critical to the recognised stages of drinking water incidents (WHO, 2008). In the proactive stage, regulatory agencies provide feedback, endorsement and verification of safety measures taken. In the initial alarm stage, these agencies provide advice and verification that relevant action is taken. In the management/control stage, they may continue to provide advice, and undertake their own verification that objectives of the intervention are achieved. In the postincident stage, their role is to ensure that the initial risk is controlled, and that measures are in place to prevent future incidents. The risk management process also recognises a proactive, analytical phase (resulting in a risk estimate) as well as a deliberative phase which involves stakeholders' input (Glicken-Turnley, 2002). Major stakeholders would include internal stakeholders (various departments in the utility that may have a stake in the issue, e.g. operations, water quality, risk management, public relations) as well as external stakeholders (e.g. public health and environmental regulators, water resources agency, water vendors, contractors, medical and health care professionals, consumer groups, community leadership). Depending on the cause, severity and impact of the incident, other important stakeholders include the Government emergency services agency, law enforcement, local politicians and the media (Bartram et al., 2009; Jalba et al., 2009). Proactively developing good relations with stakeholders during normal times is much easier than during an incident where time is limited, stakes high, and communication cautious.

Establishing the safety of drinking water involves more than just water technology. The subjective nature of risk engages perceptions, depending on the various meanings of risk held by different stakeholders (Aven, 2010). Confidence in the safety of the water supply relies on interpretation from various viewpoints, depending on trust, being up-to-date on emerging pollutants and pathogens, and being well-informed. Events or developments that may impact water quality reported in our interviews, such as human or animal bodies drowned in the water source, toxic spills from accidents happening near the catchment (e.g. highway accidents), or accidents happening during recreational, industrial or agricultural activities in the catchment, highlighting the importance of having good relationships with stakeholders.

In the absence of pre-established agreements on incident management, multiple points of contact with the media may result in conflicting messages being passed on from the various actors in the management of the drinking water incident, which can easily fuel media and public speculation about the real gravity of the event, the competence of responders or the success of control measures (Jalba et al., 2010). Political interference may occur, and delay or undermine the efforts of the incident control team if cooperation between stakeholders is 
not well-structured and tested in advance (Hrudey and Hrudey, 2004; Scottish Executive, 2002). Lastly, poor public communication (Jalba et al., 2010) may aggravate the public health consequences of the incident (Hunter and Reid, 2005).

In a drinking water incident, regulatory agencies themselves are likely to come under pressure from public, media and politicians. Good institutional relationships, particularly regulatory trust, are important for maintaining a unified 'front' against cross-criticism. Regardless, regulatory agencies typically have the last word as to whether the incident response was optimal or not. A true partnership often includes joint weathering of adversity in the cases where there is public and/or political dissatisfaction to incident response.

\subsection{What determines effective interagency relationships?}

In a drinking water emergency, all players depend on each other for critical information related to incident investigation, contamination control and public communication (Parkin et al., 2006; WHO, 2011). Many study participants indicated a crisis is the most difficult time for building relationships. Because of public interest in the matter, this relationship has to withstand sustained pressure from public, media and politicians. We suggest an effective collaborative relationship must recognise a preventive framework similar to the multiplebarrier approach advocated internationally for managing drinking water quality, meaning that all six relationship components we introduced (Jalba et al., 2010) are necessary for optimal institutional relationships. A failure in any of these presents a relationship risk, even if the other components may eventually provide enough control to prevent an interagency incident (i.e. close-call). Moreover, the components must be achieved in a meaningful, not a cursory or superficial, way. For example, mutual understanding includes an understanding of regulatory roles and good personal relationships, but also understanding the other party's working environment, their expectations, and even how to best present the information shared in a format that is most helpful to them. A collaborative attitude and top management support further creates the conditions for the continuity of the relationship. Finally, active implementation and structure firmly establishes the relationship, thus supporting consistency, preventing succession risks, and sustaining the relationship during crisis (Parkin et al., 2006).

\subsection{Effective inter-organisational collaborations are not accidental}

Developing relationships proactively takes time and commitment; there are often no 'natural' incentives in this regard for water utilities in affluent countries since drinking water incidents with public health consequences are rare (Hrudey and Hrudey, 2004). 
Nevertheless, such incidents may occur regardless of the efforts to prevent them, and a crisis is not the optimal time to 'exchange business cards'. Without a platform of trust, sharing information and expertise, and open communication between agencies, unnecessary difficulties and additional risks are present during incident management (Jalba et al., 2010).

In contrast, with the poor cooperation examples reported in the incidents we analysed, e.g. hiding or counterfeiting evidence, lying to regulators, or blocking media statements issued by other stakeholders (Jalba et al., 2010), we uncovered little evidence indicating that such behaviour would have been expected prior to the incident. In general, any prior contacts between stakeholders seemed to have been professionally amiable even if technical concerns might have been present. This was sometimes confirmed during study interviews. Mistrust, poor communication, insufficient training and a suboptimal cooperation structure seemed to have only become apparent at the time of the incident (Jalba et al., 2010). We learned that improvements were generally implemented after incidents to prevent re-occurrences, as part of the organisational learning process and/or under external pressure, i.e. Governmental investigations (Badenoch et al., 1990; Laing, 2002; LIHAG, 1989; LIHAG, 1990; McClellan, 1998c; O'Connor, 2002b), or improved regulations (OMOE, 2003). This is commendable, but reactive in approach.

Discovering the reality of institutional relationships during incidents is itself an example of poor prevention. Among participating organisations, approximately a quarter of water utilities and half of PHAs had not practised their emergency management arrangements in a joint exercise at the time of the interview. Many of their representatives affirmed they exercised their emergency arrangements 'enough' when actual incidents occur, and believed that such an approach provides adequate practise for their needs. Most of these organisations were found to lack any form of written bilateral agreements. Interviewees from these organisations expressed confidence in the status quo based on their past incident management experiences. However, the lack of formalised agreements, coupled with a lack of joint practise focusing on interagency collaboration, leaves many potential relationship gaps unrecognised. This makes them vulnerable to events that may challenge institutional collaboration in the same manner as they did in the analysed past incidents.

While it is impossible to prevent all undesirable developments, it is clear from the above that an informed, vigilant and inquisitive attitude regarding the quality of current interagency relationships would benefit both consumers and organisations involved in the area of drinking water. An adaptation of prevention principles (Axelrod, 1984) for drinking water safety should recognise three stages of prevention, namely proactively promoting relationships, 
periodically verifying the existing arrangements, and learning from collaboration challenges when they occur.

Bardach $(1998 ; 2001)$ addresses the question of whether successful inter-organisational collaborations are achieved reactively or purposefully. Without negating the role of chance interactions, a proposed "craftsmanship" model suggests successful collaborations are more likely to be achieved through an active, rather than a passive, process. This process is often conducted by visionary, committed individuals, skilled in the art of "boundary spanning" (Williams, 2002).

The role of external pressures in developing institutional relationships among participating organisations was clearly identified and the presence of relationship advocates was correlated with a better recognition of the critical relationship components (Jalba et al., 2010) than the average participating organisation, while the presence of external pressures did not significantly correlate to such understanding.

Our findings clearly indicate that effective inter-organisational relationships are not accidental. Good institutional collaborations identified among participating organisations did not develop neither randomly nor naturally. In some cases, the appreciation of the value of good institutional relationships may have occurred as a result of past incidents aggravated by defective relations (Jalba et al., 2010). More often, such appreciation developed in less dramatic circumstances, where an incident or close-call was eventually managed successfully, but post-incident analysis revealed suboptimal relationships, which may have delayed incident control and recovery. For example, political interference into the incident command system process led participating organisations to formulate a better structure and guidelines that would prevent politicians from disturbing incident response (Scottish Executive, 2002). In some organisations, the presence of 'enlightened individuals' on both sides catalysed the process.

Learning from experience is vitally important. For provision of drinking water, incidents and close-calls (in one's own organisation, or elsewhere) represent an important source of learning that is often underused. Systematically learning from close-calls is at least as important as analysing generic, catastrophic scenarios, yet often risk managers may focus on the latter. While the importance of learning from close calls as a risk management tool was advocated by many of the participating utility representatives, most PHA interviewees did not seem to recognise the critical role that this approach can play in preventing drinking water safety incidents. Their lack of knowledge about how utilities in their area approach this 
aspect of learning is likely to limit the extent to which the PHA can encourage and support a fully preventive risk management approach among their partners.

While each have their place in developing a risk management culture, effective interagency collaborations are more likely to develop from jointly practising meaningful, likely scenarios based on past experiences, rather than relying only on the odd generic 'Hollywood-type' disaster management exercise. 'Likely' scenarios may also involve less resources, can be organised regularly, and will provide multiple opportunities for interaction between key people in both organisations. Past incidents with collaboration difficulties may inform more meaningful and less repetitive scenarios whose practice will improve aspects of institutional relationships components and determinants that are critical to their mission.

If developing an effective institutional relationship is rarely accidental, the same applies to maintaining the momentum of the relationship, or 'sustaining innovation' (Schall, 1997). An important challenge for participating organisations seemed to be keeping interagency relationships 'alive' when disasters or major incidents do not occur. Relationships are dynamic entities, tested in time by routine incidents (as well as lack of) with rotation of staff in key positions.

Successful 'boundary-spanners' (Williams, 2002) are skilled at identifying ways to maintain regular contact between organisations; this includes 'orchestrating' [artificial] opportunities to keep the momentum going (Table 3). Creative managers find no shortage of opportunities in the space between organisational barriers because they are less bound by preexisting patterns and routines. Such initiatives may include setting up 'boundary organisations' or 'boundary objects' (Cash et al., 2003) in the form of interdisciplinary bodies or collaborative projects that bring together organisations with the purpose of addressing common interests (Tables 3 and 4). Cross-boundary entities filling gaps between organisations are more likely to engage parties by increasing the salience of information produced, credibility of initiative and a ensuring a more transparent process (Cash et al., 2003). In the area of drinking water, possible examples include local/regional water quality committees, organised seminars or training events on interdisciplinary topics of common interest, joint research projects or formulating joint emergency response guidelines. Other initiatives may include inviting key people to become familiar with their own organisation's operations, for example through a guided visit at the local water treatment plant.

Many participants in this study failed to recognise succession risks to institutional relationships, particularly on the PHA side. As Schall (1997) notes, rather than relying on key people's immortality, responsible managers in charge of the institutional relationship 
should use succession planning strategies. In more proactive organisations, managers are actively looking for new potential champions of the relationship in their organisation, delegating them on a rotation basis to represent them in key interagency activities (be that regular communication, joint meetings, expertise sharing, or common projects), and investing in their training. Creating multiple contact points between the partners establishes a wider support within each organisation, thus enhancing resilience. Skilled managers also identify opportunities to 'hardwire' the relationship in organisational procedures, such as embedding interagency communication and interdisciplinary training in their culture. By engaging key stakeholders in multi-agency activities, they establish a wider support in the community (Jalba et al., 2009). Finally, by promoting recognition of the advantages of the relationship, its discontinuation may later be perceived as a strategic risk (Schall, 1997). One could hypothesise that employing an active, coordinated approach to preserving the momentum of the relationship makes it difficult to cease even when confronted with difficult times and competing priorities.

\subsection{Regulation is necessary, but not sufficient in isolation}

Adopting regulations and guidelines that require stakeholders to work together on a common task (e.g. WSPs, ERPs) is a step toward promoting an environment where more institutional contacts occur (Bartram et al., 2009; Jalba et al., 2009; NHMRC, 2004b; USEPA, 2004a; USEPA, 2004c; WHO, 2008). Regulatory frameworks may encourage interagency collaboration to complete their requirements; however there is less certainty about what will happen once mandated documents are developed. Would introducing more regulations that require agencies to connect take care of all institutional relationship deficiencies noticed in past incidents? Will 'indirectly mandating' interagency cooperation via requirements such as WSPs, ERPs, vulnerability assessments and so on ensure that water utilities and their stakeholders will develop all necessary components of an effective relationship? These questions raise the issue of whether effective interagency relations are more likely to be achieved reactively or purposefully. This is complex and may require further research; however some preliminary observations can be offered on the basis of this study.

Prior to the development of a 'risk management culture', utilities and their oversight agencies involved in the incidents did not operate in a legislative vacuum. During the last three decades when these incidents occurred, regulations were generally in place to mandate, for example, oversight of the safety of water supply operations, or empowering PHAs to 
investigate and enforce public health protection if they suspected that the water supply is unsafe. Indeed, relationships between key people existed in many cases even before the incidents we studied (Jalba et al., 2010; Laing, 2002; McClellan, 1998c; O'Connor, 2002a). What was missing, however, was an agreed standard of what a meaningful interaction between agencies represented as a means to help them discharge their mandates successfully.

Both environmental and public health enforcement officers had a 'relationship' with Walkerton water supply operators, which at that time was regarded as acceptable (O'Connor, 2002a; Perkel, 2002). The latent deficiencies only became apparent when the water supply became severely contaminated with pathogens (O'Connor, 2002a). While the results of regulatory inspections of both Walkerton and North Battleford water systems prior to the incidents were inadequate (Laing, 2002; O'Connor, 2002a), it is easy to forget fearing a problem that rarely occurs (Reason, 1997), and accept the status quo. The authority of enforcement officers may have been real, but in the 'real world' there are many factors that may limit their effectiveness. In the absence of a true collaborative relationship, both persuasion and regulatory coercion are less likely to produce the desired changes.

Rather than increasing regulation, a different mindset may be required from water utilities and oversight agencies alike (Pollard et al., 2009). A productive relationship differs from a 'mandated' relationship. Should interagency relationships remain unrecognised as an essential 'ingredient' of successful risk management in the area of drinking water, development of WSPs, ERPs or vulnerability assessments may become another lost opportunity. As Pollard et al. (2009) note, introducing new standards such as WSPs while ignoring related human factors may not prevent them from becoming another cursory or superficial exercise, i.e. something to produce, file and then move on doing things as before, or even documenting under a new template what the organisation already does, rather than stimulating improvements. Drawing from the experience of implementing the international quality standard ISO 9000 and the introduction of the hazards analysis and critical control point (HACCP) approach, Pollard et al. (2009) emphasizes that both meaningful and superficial implementation are possible, depending on the organisational 'mindfulness' culture.

If effective inter-organisational relationships are clearly recognised as important for the successful provision of drinking water, they are more likely to be sought purposefully than being left to chance. If organisations choose to pursue them in the same way that they pursue other functions such as treatment operations, business opportunities, risk management or public relations, then they may take steps to stimulate and 'hardwire' the collaborative 
performance of their staff and of the organisation as a whole. Mindful organisations may choose to select, train and reward their staff based on their collaborative performance (Daley, 2009), such as interdisciplinary communication skills, engaging stakeholders, and building trust in their product. Mutual recognition of the importance of interagency relations between water utilities, oversight agencies, and other stakeholders, is also likely to encourage sharing of expertise and critical information.

\subsection{Assessing relationship performance}

Awareness, of the quality of one's organisation institutional relationships, as well as of the type of relationship gaps that aggravated past incidents and how they occurred is likely to be the most powerful motivator for developing effective interagency relationships. A systematic verification of effective interagency relationships was recommended in Pollard et al. (2009) based on research findings and guidance literature on inter-organisational relationship performance (Daley, 2009; ISO, 2007; OECD, 2003). The proposed framework for performance evaluation of institutional relationships was based on outcome and activity relationship performance indicators during both normal and emergency times. This framework was designed to ensure that all six relationship components we introduced are considered when water utilities formulate their local risk management strategy relating to cooperation with regulatory agencies.

\subsection{Interdisciplinary training}

Apart from in-house training, institutional relations may be promoted by involving the other party's representatives in common research and community projects by implementing interdisciplinary training for key people involved in the relationship, and by discussing issues of mutual interest such as monitoring and controlling emerging pathogens, or concerns over long-term effects of chemicals or disinfection by-products (DBPs). The related practical skills may be developed through incident and close call debriefing, case studies, joint exercises on emergency response plans, or responding to mutual assistance agreements with other peer organisations.

The success of such training is best tested using simulations based on realistic scenarios, preferably adapted from real incidents that happened in their organisation or elsewhere. The use of realistic joint simulations is likely to give a practical understanding of major training themes, such as each other's response protocols, how to identify resources, understanding which entities are likely to be involved in an incident, matching epidemiology findings with 
distribution infrastructure, challenges of risk communication with a potentially distrusting public, as well as limitations of water quality monitoring, of data interpretation and of the risk assessment approach.

Finally, key people involved in the institutional relationship must have a practical and realistic view of what the other party needs to know, can possibly know and can be expected to be able to do in a drinking water incident, and what expertise and resources can be expected from them. One of the findings of our research was that mutual expectations in terms of training, expertise and ability to address concerns may not always match the standard training provided for professionals on the other side, or even with what can realistically be expected from them. This leaves many grey areas of expertise that may not always be obvious during routine business, but which might become apparent during a challenging situation.

Water operators may not always be able to: identify the source of contamination in the water system (Carrique-Mas et al., 2003); unconditionally support a prolonged or 'blanket' boil order that as a precaution covers many areas where the risk is highly unlikely but cannot be entirely excluded (McClellan, 1998a; McClellan, 1998b); decide what is the relevant information that must be shared with other agencies (Laing, 2002); or corroborate epidemiologically derived indications of water supply contamination with possible water system barrier failures (Hrudey and Hrudey, 2004).

On their side, PHA personnel may not always be able to: justify the epidemiological link of an outbreak to the water supply beyond reasonable doubt (e.g. South Devon cryptosporidiosis outbreak in Hrudey and Hrudey, 2004), judge the risk of transmission via water in comparison with other exposure pathways (e.g. Victoria toxoplasmosis outbreak in Hrudey and Hrudey, 2004), or provide laboratory support for detecting pathogens that may be routinely detected in clinical samples. This is because a detection method from water samples may not be available, or because pathogens multiply in humans, but not in the water, so the negative predictive value (probability of a negative result being truly negative) of the method is much lower for water quality testing than for stool sample testing (Allen et al., 2000).

\subsection{Study limitations}

Adopting a qualitative approach to studying the collaboration between water utilities and PHAs has helped to identify a multitude of themes. At the same time, the generalisation of findings of this study is limited by purposively sampling a selection of organisations in order 
to investigate a variety of organisational cultures. Another study limitation relates to interviewing only the most experienced people as far as the institutional relationship is concerned. The relationship between better interagency collaboration and safer drinking water has been explored here only qualitatively but our findings reinforce the intuition that better collaboration has merit and is needed in most cases.

\section{Conclusions}

Would better institutional relationships have avoided the high profile water quality incidents of recent decades discussed in Hrudey and Hrudey (2004)? Even optimal interagency relationships cannot prevent contamination from entering the water supply, and no relationships can assure contamination-proof systems. Equally, no amount of collaboration (or technology, for that matter) can prevent unforeseen hazards such as a pathogenic Cryptosporidium-carrying rabbit infiltrating the waterworks (Chalmers et al., 2009) or a relief worker depositing treatment chemicals in the wrong place in the system (LIHAG, 1989), though certain technological and managerial improvements would have made such situations less likely.

On the other hand, with the Walkerton incident as an example, poor institutional relationships can result in excessive energy, time and resources being spent trying to obtain the right information about what went on, thereby severely delaying control of an outbreak, resulting in high public inquiry costs, and an expensive out-of-court settlement of a classaction lawsuit (O'Connor, 2002a). In the North Battleford incident, much time was unnecessarily wasted; by PHA investigators who were unaware of drinking water system problems (Laing, 2002). Poorly managed interagency relations in the Sydney incident led to a loss of institutional credibility and costs of several Government inquiries (Hrudey and Hrudey, 2004). In the Camelford incident, poor interagency communication led to a serious loss of credibility, costs of Government inquiries, psychological and psychosomatic suffering, and legal action (COT, 2005; DOH, 2005). So we conclude:

(1) A responsible water utility fosters good relationships with their PHA counterparts. A responsible PHA is likely to respond in-kind.

(2) An effective institutional relationship is often determined by the successful achievement of at least six relationship components: trust, communication, shared expertise, common interdisciplinary training, supporting regulation and proactivity. 
Together, these components will act as a multiple-barrier protection from interorganisational conflicts.

(3) Some of the participating organisations in this study demonstrated practices that sought intuitively to develop these components. However, most lacked a targeted approach and, as a result, not all relationship components were found to be optimal.

(4) The use of risk terminology does not necessarily imply the existence of a risk management culture, and meanings can vary greatly. A common risk management paradigm may need to be formulated regarding collaboration between water utilities and PHAs.

(5) The pros and cons of the interventionist versus naturalist approach to interagency relations for drinking water may remain a subject for philosophical debates. However, the study evidence clearly supports the adage that "prevention is better than cure'. A 'natural', evolutionary, process of developing inter-organisational relationships may well be advocated by ignoring the 'red flags' identified in this study. On the other hand, proactively implementing the lessons from past incidents and the successful current practices would clearly reduce inherent adverse consequences.

\section{Acknowledgements}

The authors are grateful for the input of the water and public health professionals that informed this paper. Research on the themes raised is being funded by the Water Research Foundation (former Awwa Research Foundation). The authors acknowledge the Water Research Foundation (TC3184, Cranfield University) is the joint owner of the technical information upon which this manuscript is based. This research also benefited from funding from the Canadian Water Network, the Natural Sciences and Engineering Research Council of Canada, and a consortium of international water utility companies and organizations.

\section{References}

Allen MJ, Clancy JL, Rice EW. The plain, hard truth about pathogen monitoring. J Am Water Works Assoc 2000; 92: 64-76.

Aven T. On the Need for Restricting the Probabilistic Analysis in Risk Assessments to Variability. Risk Analysis 2010; 30: 354-60.

Axelrod R. The Evolution of Cooperation. New York: Basic Books, 1984. 
Badenoch J, C. L. R. Bartlett, C. Benton, D. P. Casemore, R. Cawthorne, F. Earnshaw, et al. Cryptosporidium in Water Supplies. HMSO, Department of the Environment, Department of Health, London, 1990, pp. 230.

Bardach E. Getting Agencies to Work Together: The Practice and Theory of Managerial Craftsmanship. Washington, DC: Brookings Institution Press, 1998.

Bardach E. Developmental Dynamics: Interagency Collaboration as an Emergent Phenomenon. Journal of Public Administration Research and Theory 2001; 11: 149-164.

Bartram J, Corrales L, Davison A, Deere D, Drury D, Gordon B, et al. Water safety plan manual: step-by-step risk management for drinking-water suppliers. World Health Organisation, Geneva, Switzerland, 2009, pp. 101.

Carrique-Mas J, Andersson Y, Petersen B, Hedlund KO, Sjogren N, Giesecke J. A norwalklike virus waterborne community outbreak in a Swedish village during peak holiday season. Epidemiol Infect 2003; 131: 737-44.

Cash DW, Clark WC, Alcock F, Dickson NM, Eckley N, Guston DH, et al. Knowledge systems for sustainable development. Proceedings of the National Academy of Sciences 2003; 100: 8086-8091.

CEC. Pricing policies for enhancing the sustainability of water resources. COM(2000) 477 final. Comission of the European Communities, Brussels, 2000.

Chalmers RM, Robinson G, Elwin K, Hadfield SJ, Xiao L, Ryan U, et al. Cryptosporidium Rabbit Genotype, a Newly Identified Human Pathogen. Emerg Infect Dis 2009; 15: 829830.

COT. Subgroup Report on the Lowermoor Water Pollution Incident. Committee on Toxicity of Chemicals in Food, Consumer Products and the Environment, London, 2005, pp. 448.

Daley DM. Interdisciplinary Problems and Agency Boundaries: Exploring Effective CrossAgency Collaboration. Journal of Public Administration Research and Theory 2009; 19 : 477-493.

DOH. Public meeting held at 19:30 in Camelford Hall, Clease Road, Camelford PL32 9PE to discuss the Draft Report of the COT Subgroup on the Lowermoor Water Pollution Incident. Department of Health, London, UK, 2005, pp. 91 pp.

Emde KME, Smith DW, Talbot JA, Gammie L, Ancel S, Fok N, et al. Estimating Health Risks from Infrastructure Failures. Efficient and Customer-Responsive Organization. AWWA Research Foundation, Denver, CO, 2006.

Glicken-Turnley J. Risk Assessment in Its Social Context. In: Paustanbach DJ, editor. Human and Ecological Risk Assessment. John Wiley \& Sons, Inc., 2002, pp. 1359-1376. 
Goulding C. Grounded Theory: A Practical Guide for Management, Business and Market Researchers. London: Sage, 2002.

Gray B. Collaborating: Finding Common Ground for Multiparty Problems: Jossey-Bass, 1989.

Herrick C, Pratt J, Raucher R, Kalas-Adams N, Cotruvo J, Darr-Bornstein K, et al. Emergency Response and Recovery Planning for Water Systems: A Kit of Tools. Efficient and Customer-Responsive Organization. AWWA Research Foundation, Denver, CO, 2006, pp. 65

Hrudey SE. Drinking-Water Risk Management Principles for a Total Quality Management Framework. Journal of Toxicology and Environmental Health. 2004; Part A: 1555-1566. Hrudey SE, Hrudey EJ. Safe Drinking Water: Lessons from Recent Outbreaks in Affluent Nations. London, UK: IWA Publishing, 2004.

Hrudey SE, Hrudey EJ, Pollard SJT. Risk management for assuring safe drinking water. Environment International 2006; 32: 948-957.

Hunter PR, Reid M. Poor Communication During a Contamination Event May Cause More Harm to Public Health than the Actual Event Itself. In: Thompson KC, Gray J, editors. Water Contamination Emergencies: Enhancing Our Response. The Royal Society of Chemistry, Manchester, UK, 2005, pp. 156-164.

ISO. ISO/PAS 22399 Societal security - Guideline for incident preparedness and operational continuity management. International Organisation for Standardization, Geneva, Switzerland, 2007, pp. 31.

IWA. The Bonn Charter for Safe Drinking Water. International Water Association, London, UK, 2004, pp. 18.

Jalba DI, Cromar NJ, Pollard SJT, Charrois JW, Bradshaw R, Hrudey SE. Safe drinking water: Critical components of effective interagency relationships. Environment International 2010; 36: 51-59.

Jalba DI, Hrudey SE. Drinking Water Safety and Risk Management for Public Health Agencies. Environmental Health Review - Journal of the Canadian Institute of Public Health Inspectors 2006; 50.

Jalba DI, Tuite S, Mercer J, Charrois JW, Cromar NJ. Information and Data Requirements for Implementing and Assessing Frameworks of Drinking Water Safety. World Health Organisation, Geneva, Switzerland, 2009.

Krames JA. The Strategic Drucker. Inside Drucker's Brain. Portfolio (Penguin Group), New York, NY, 2008, pp. 224. 
Laing RD. Report of the Commission of Inquiry into Matters Relating to the Safety of the Public Drinking Water in the City of North Battleford, Saskatchewan. Department of Justice, Government of Saskatchewan, Regina, SK, 2002, pp. 372.

LIHAG. Water pollution at Lowermoor North Cornwall - Report of the Lowermoor Incident Health Advisory Group. HMSO, London, UK, 1989, pp. 22.

LIHAG. Water pollution at Lowermoor North Cornwall - Second report of the Lowermoor Incident Health Advisory Group. HMSO, London, UK, 1990, pp. 51.

Maxwell JA. Conceptual framework: What do you think is going on? Qualitative Research Design: An Interactive Approach (2nd edition). Sage Publications, 2004, pp. 46-54.

McClellan P. Second Interim Report. Sydney Water Inquiry. New South Wales Premier's Department, Sydney, NSW, 1998a.

McClellan P. Third Interim Report. Sydney Water Inquiry. New South Wales Premier's Department, Sydney, NSW, 1998 b.

McClellan P. Final Report. Sydney Water Inquiry. New South Wales Premier's Department, Sydney, NSW, 1998c.

Middleton J, Saunders P. Paying for water. Journal of Public Health Medicine - Oxford University Press 1997; 19: 106-115.

Miller G, Dingwall R, Murphy E. Chapter 17. Using qualitative data and analysis:

Reflections on organizational research. In: Silverman D, editor. Qualitative Research:

Theory, Method and Practice. Sage Publications, London, 2004, pp. 378.

Mobley J, Tatham E, Reinhardt K, Tatham C. Strategic Communication Planning: A Guide for Water Utilities. Efficient and Customer-Responsive Organization. AWWA Research Foundation, Denver, CO, 2006, pp. 84.

Morse JM, Field P-A. Qualitative research methods for health professionals. Beverly Hills, CA.: Sage Publications Inc, 1995.

NHMRC. Chapter 3: Framework for Management of Drinking Water Quality - the twelve elements. Australian Drinking Water Guidelines. National Health and Medical Research Council, Canberra, ACT, 2004b.

O'Connor DR. Report of the Walkerton Inquiry. Part One: The Events of May 2000 and Related Issues. The Walkerton Inquiry, Toronto, ON, 2002a.

O'Connor DR. Report of the Walkerton Inquiry. Part Two: A Strategy for Safe Water. The Walkerton Inquiry, Toronto, ON, 2002b.

OECD. Guidance on Safety Performance Indicators. Organisation for Economic Cooperation and Development, 2003, pp. 212. 
OMOE. Drinking Water Systems under O. Reg. 170/03. Accessed 2009. Ontario Ministry of the Environment, , Toronto, ON, 2003.

Parkin R, Ragain L, Bruhl R, Deutsch H, Wilborne-Davis P. Advancing Collaborations for Water-Related Health Risk Communication. Efficient and Customer-Responsive Organization. AWWA Research Foundation, Denver, CO, 2006, pp. 204.

Parkin R, Ragain L, Embrey M, Peters C, Butte G, Thorne S. Risk Communication for Emerging Contaminants. Efficient and Customer-Responsive Organization. AWWA Research Foundation, Denver, CO, 2004, pp. 116.

Perkel CN. Well of Lies: The Walkerton Water Tragedy. Toronto, ON: McClelland \& Stewart, 2002.

Pollard S, Bradshaw R, Tranfield D, Charrois J, Cromar N, Jalba D, et al. Developing a Risk Management Culture - 'Mindfulness' in the International Water Utility Sector (TC3184). Water Research Foundation, Denver, CO, 2009, pp. 117.

Pollard S, Hrudey S, Hamilton P, MacGillivray B, Strutt J, Sharp J, et al. Risk analysis strategies for credible and defensible utility decisions. Awwa Research Foundation, American Water Works Association and IWA Publishing, Denver, CO, 2007, pp. 88.

Pollard SJT. Risk management for water and wastewater utilities. London, UK: IWA Publishing, 2008.

Pollard SJT, Strutt JE, MacGillivray BH, Hamilton PD, Hrudey SE. Risk analysis and management in the water utility sector - a review of drivers, tools and techniques. Trans. IChemE Part B: Process Saf. Environ. Prot. 2004; 82: 453-462.

Pollard, S.J.T., Gormley, Á., Shaw, H., Mauelshagen, C., Hrudey, S.E., Owen, D., Miller, G., Fesko, P. and Pritchard, R. Risk governance: an implementation guide for water utilities, Water Research Foundation, Denver, Co., US, 2013.

Reason J. Managing the risks of organisational accidents. Brookield, VT: Ashgate Publ., 1997.

Rizak S, Hrudey S. Research Report 37: Strategic Water Quality Monitoring for Drinking Water Safety. The Cooperative Research Centre for Water Quality and Treatment, Salisbury, SA, 2007, pp. pp. 51-56.

Schall E. Public-Sector Succession: A Strategic Approach to Sustaining Innovation. Public Administration Review 1997; 57: 4-10.

Scottish Executive. Investigation into the implementation of the Cryptosporidium (Scottish Water) Directions 2002 in Scotland. Scottish Executive, Edinburgh, Scotland, UK, 2002, pp. 87. 
Silverman D. Chapter 2. What is qualitative research? Interpreting Qualitative Data: Methods for Analyzing Talk, Text and Interaction. Sage Publications Ltd, London, UK, 2001, pp. 325 .

Thomson AM, Perry JL, Miller TK. Conceptualizing and Measuring Collaboration. Journal of Public Administration Research and Theory 2009; 19: 23-56.

Trochim WMK. Research Methods Knowledge Base: Qualitative Approaches. Retrieved January 2010. Web Center for Social Research Methods, 2006.

USEPA. Emergency Response Plan Guidance for Small and Medium Community Water Systems to Comply with the Public Health Security and Bioterrorism Preparedness and Response Act of 2002. United States Environmental Protection Agency, 2004a.

USEPA. Summary Report. National Water Security Risk Communication Symposium, San Francisco, CA, 2004b, pp. 109.

USEPA. Requirements of the Public Health Security and Bioterrorism Preparedness and Response Act of 2002 (Bioterrorism Act). 2013. United States Environment Protection Agency, 2004c.

USEPA. Summary Report. National Water Security Risk Communication Symposium. US

Environmental Protection Agency, San Francisco, CA, 2005, pp. 109 pp.

WHO. Tools for assessing the O\&M status of water supply and sanitation in developing countries. World Health Organisation, Geneva, 2000.

WHO. Guidelines for drinking-water quality - Third edition, incorporating the first and second addenda. Vol. 1, Recommendations. World Health Organization, 2008, pp. 515. WHO. Guidelines for Drinking-water Quality - fourth edition. World Health Organisation, Geneva, Switzerland, 2011, pp. 541.

Williams P. The Competent Boundary Spanner. Public Administration Review 2002; 80: 103-24.

Williams T, Hrudey S. Public Health Protection Demands Effective Communication International Water Association - Bonn principles series 2007: 1-4. 


\section{$1 \quad$ List of Tables captions}

2

3

4

5

6

7

8

Table 1: Opportunities for developing a relationship between a water utility and a PHA

Table 2: Views of both parties on PHA expectations of the water utility

Table 3: Views of both parties about utility expectations of the PHA 


\begin{tabular}{|c|c|}
\hline Opportunity & Examples \\
\hline Legislation & $\begin{array}{l}\text { - Requirements to develop WSPs; } \\
\text { - Regulatory requirement to develop a common } \\
\text { MoU; } \\
\text { - Working out joint incident response protocols; } \\
\text { - Developing emergency response plans and } \\
\text { vulnerability assessments (particularly after } \\
\text { September 11,2001); }\end{array}$ \\
\hline Incidents & $\begin{array}{l}\text { Waterborne outbreaks (e.g. Cryptosporidiosis). } \\
\text { - Successful management of a drinking water and } \\
\text { health crisis that involved the PHA; } \\
\text { - Desire to understand each other's business after } \\
\text { suboptimal incident management coordination; }\end{array}$ \\
\hline Public concerns & $\begin{array}{l}\text { - Concerns about lead contamination in distribution; } \\
\text { - Concerns about Cryptosporidium from the AIDS } \\
\text { community, working on a common communication } \\
\text { strategy; } \\
\text { - Concerns on long-term effects of disinfection by- } \\
\text { products (DBPs) or fluoride; } \\
\text { - Health concerns over intensive agriculture projects } \\
\text { that would impact source water quality; }\end{array}$ \\
\hline $\begin{array}{l}\text { Requests for } \\
\text { assistance }\end{array}$ & $\begin{array}{l}\text { - Uncertainties on interpretation of Cryptosporidium } \\
\text { tests resulting in working out a common protocol; } \\
\text { - Water utility requesting PHA to interpret recent } \\
\text { studies on new DBPs; } \\
\text { - PHA requesting assistance with water samples } \\
\text { analysis for recreational water or other non- } \\
\text { drinking water related issues; } \\
\text { - PHA requesting assistance on borderline projects } \\
\text { (e.g. lead contamination from building plumbing). }\end{array}$ \\
\hline Joint projects & $\begin{array}{l}\text { Community drinking water safety educational } \\
\text { projects; } \\
\text { Drinking water safety research projects; }\end{array}$ \\
\hline Other & $\begin{array}{l}\text { Environmental regulator inspections that pointed } \\
\text { out deficiencies, resulting in the involvement of } \\
\text { the PHA in discussions over upgrading water and } \\
\text { sewage systems; } \\
\text { - Utility paying for PHA staff dedicated to drinking } \\
\text { water quality. }\end{array}$ \\
\hline
\end{tabular}


Table 2: Views of both parties on PHA expectations of the water utility

\begin{tabular}{|c|c|c|}
\hline $\begin{array}{l}\text { Expectations } \\
\text { category }\end{array}$ & PHA participants views & Utility participants views \\
\hline $\begin{array}{l}\text { Incident } \\
\text { management }\end{array}$ & $\begin{array}{l}\text { Able to recognise when drinking water contamination occurs; } \\
\text { - Will perform a risk assessment related to any contamination } \\
\text { event; } \\
\text { - Is able to correlate water quality testing results with operational } \\
\text { conditions; } \\
\text { - Provides recommendations for public health protection; }\end{array}$ & $\begin{array}{l}\text { Able to provide assurance when the system functions } \\
\text { normally; } \\
\text { - Identify location of the system problem and isolates it } \\
\text { from the rest of the system; } \\
\text { - Explain issues, concerns and options from utility } \\
\text { perspective; } \\
\text { - Clearly define the area of service potentially affected; } \\
\text { - Propose control options in the case of public health } \\
\text { risks; }\end{array}$ \\
\hline Knowledge & $\begin{array}{l}\text { - Is able to describe the relevant properties of the chemical of } \\
\text { concern (e.g. source, formation, removal options, and how it is } \\
\text { regulated); } \\
\text { - Has information on emerging pathogens; }\end{array}$ & $\begin{array}{l}\text { - Able to describe contaminant and know how to test for } \\
\text { it; } \\
\text { - Well-informed on common problems; } \\
\text { - Well-informed on water industry best practices; }\end{array}$ \\
\hline Responsiveness & $\begin{array}{l}\text { Provide timely and accurate information; } \\
\text { - Respond promptly to PHA inquiries; } \\
\text { - Provide timely notification of adverse results, investigations } \\
\text { results and any incident control decisions; } \\
\text { - Investigate for water system problems when suspicion is raised, } \\
\text { e.g. by enhancing sampling and testing; }\end{array}$ & $\begin{array}{l}\text { - Provide PHA with adverse monitoring results and } \\
\text { related technical and operational data in a timely, } \\
\text { honest and transparent manner; } \\
\text { - Prompt notification of any unusual events with } \\
\text { potential public health consequences; } \\
\text { - Prompt investigation of water system problems; } \\
\text { - Enhancing water quality sampling and testing; }\end{array}$ \\
\hline Public support & - Unconditionally supports PHA public notices (including & - Will not remove or try to remove a boil water notice \\
\hline
\end{tabular}




\begin{tabular}{|c|c|c|}
\hline & $\begin{array}{l}\text { conditions to lift them); } \\
\text { - Participates in joint media statements; }\end{array}$ & until the PHA is convinced that their water is safe; \\
\hline $\begin{array}{l}\text { Partnership } \\
\text { approach }\end{array}$ & $\begin{array}{l}\text { Complete transparency in communication; } \\
\text { - Invites PHA input in their investigation (e.g. sampling strategy), } \\
\text { to discuss control options (e.g. treatment, system shutdown), and } \\
\text { their consequences; } \\
\text { - Participates in PHA investigation by describing the water system, } \\
\text { current operating conditions and reporting recent system changes; } \\
\text { - Participates in corroborating and interpreting epidemiological } \\
\text { data within the context of their system; } \\
\text { Utility laboratory will cooperate with the public health lab to } \\
\text { develop a pathogen detection method and serotyping techniques. }\end{array}$ & - Offers full cooperation throughout the incident. \\
\hline
\end{tabular}


Table 3: Views of both parties about utility expectations of the PHA

\begin{tabular}{|c|c|c|}
\hline $\begin{array}{l}\text { Expectations } \\
\text { category }\end{array}$ & Utility participants views & PHA participants views \\
\hline Public support & $\begin{array}{l}\text { - Present a joint front during public communications } \\
\text { - Provide health education to the public (including } \\
\text { contaminant fact sheets on pathogens and chemicals of } \\
\text { concern); } \\
\text { - Protect water utility customer confidentiality; }\end{array}$ & 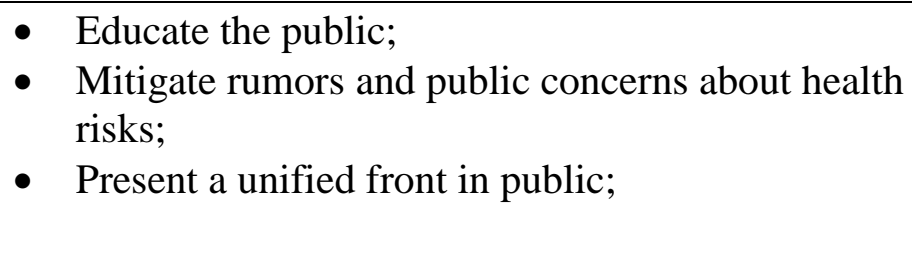 \\
\hline Partnership & - Clearly outline their expectations and be & - Provide location of cases \\
\hline
\end{tabular}




\begin{tabular}{|c|c|c|}
\hline approach & $\begin{array}{l}\text { reasonable/realistic about what can be achieved; } \\
\text { - Notify the utility on potential waterborne disease; } \\
\text { - Provide location of cases in an outbreak } \\
\text { - Provide updates on population impact in a waterborne } \\
\text { outbreak; } \\
\text { - Place drinking water risks in the general public health } \\
\text { context by weighting drinking water against other } \\
\text { exposure pathways (e.g. nitrosamines in food); } \\
\text { - Seek clarification when water monitoring and } \\
\text { epidemiological data are incongruent; }\end{array}$ & $\begin{array}{l}\text { - Provide related disease statistics } \\
\text { - } \quad \text { Notify on potentially related cases; } \\
\text { - Periodically update water utility on the public } \\
\text { health investigation; }\end{array}$ \\
\hline Regulatory support & $\begin{array}{l}\text { - Advise on regulatory guidelines; } \\
\text { - Issue public alerts (e.g. boil order) } \\
\text { - Notify general practitioners in their area. } \\
\text { - Assist water utility with reaching out to other Government } \\
\text { agencies (e.g. catchment management); }\end{array}$ & $\begin{array}{l}\text { - Facilitate contact with local hospitals, other PHAs, } \\
\text { and other Government agencies }\end{array}$ \\
\hline
\end{tabular}

